\title{
PEMBUATAN BRIKET CANGKANG KEMIRI SEBAGAI BAHAN BAKAR ALTERNATIF BAGI MASYARAKAT PEDALAMAN DI KABUPATEN ALOR
}

\author{
Loth Botahala ${ }^{1 *}$, Yulius Nixon Tena ${ }^{2}$, Moses Dulweni ${ }^{3}$, Martinus B. Litbagai ${ }^{4}$, Magdalena \\ Maukafeli ${ }^{5}$, Martha Erityana Latipra ${ }^{6}$, Kristiana Dolu Utang ${ }^{7}$, Mariam Alota ${ }^{8}$, Nelania \\ Lapaimou $^{9}$ \\ ${ }^{1}$ Program Studi Kimia, Fakultas Matematika dan Ilmu Pengetahuan Alam, \\ Universitas Tribuana Kalabahi, Kabupaten Alor, Nusa Tenggara Timur, Indonesia 85813 \\ 2,3,8Program Studi Agribisnis, Fakultas Pertanian, \\ Universitas Tribuana Kalabahi, Kabupaten Alor, Nusa Tenggara Timur, Indonesia 85813 \\ ${ }^{4}$ Program Studi IPT, Fakultas Keguruan dan Ilmu Pendidikan, \\ Universitas Tribuana Kalabahi, Kabupaten Alor, Nusa Tenggara Timur, Indonesia 85813 \\ ${ }^{5}$ Program Studi Bahasa Inggris, Fakultas Keguruan dan Ilmu Pendidikan, \\ Universitas Tribuana Kalabahi, Kabupaten Alor, Nusa Tenggara Timur, Indonesia 85813 \\ ${ }^{6}$ Program Studi Manajemen, Fakultas Ekonomi, \\ Universitas Tribuana Kalabahi, Kabupaten Alor, Nusa Tenggara Timur, Indonesia 85813 \\ ${ }^{7,9}$ Program Studi Teknologi Hasil Pertanian, Fakultas Pertanian, \\ Universitas Tribuana Kalabahi, Kabupaten Alor, Nusa Tenggara Timur, Indonesia 85813 \\ ${ }^{*}$ Korespondensi: botahala@gmail.com
}

Diterima 22 Oktober 2020 / Disetujui 23 November 2020

\begin{abstract}
ABSTRAK
Cangkang kemiri merupakan bagian dari buah kemiri yang telah menjadi limbah bagi sebagianmasyarakat, terutama penduduk desa penghasil buah kemiri. Tujuan program pengabdian kepada masyarakat ini adalah untuk memberikan edukasi dan praktek pembuatan briket dengan memanfaatkan limbah cangkang kemiri sebagai bahan baku utama. Hasil Pengabdian kepada Masyarakat menunjukkan bahwa masyarakat Desa Maikang Kecamatan Alor Selatan Kabupaten Alor-NTT telah memperoleh pengetahuan tentang peluang pemanfaatan cangkang kemiri dalam pembuatan briket sebagai alternatif bahan bakar sekaligus telah memperoleh pengetahuan tentang cara pembuatan briket.
\end{abstract}

Kata kunci: briket, cangkang kemiri, limbah, masyarakat, Desa Maikang

\section{ABSTRACT}

Candlenut shell is part of the candlenut fruit which has become a waste for some people, especially the villagers who produce candlenut fruit. The purpose of this community service program is to provide education and practice of making briquettes by utilizing hazelnut shell waste as the main raw material. The results of community service show that the people of Maikang Village, Alor Selatan Subdistrict, Alor Regency, NTT have obtained knowledge about the opportunities for using candlenut shells in making briquettes as an alternative fuel as well as obtaining knowledge about how to make briquettes.

Keywords: briquettes, candlenut shells, waste, community, Maikang village 


\section{PENDAHULUAN}

Pemanasan global dipicu oleh diakibatkan baik oleh adanya aktifitas makluk hidup maupun terjadi secara alamiah. Gas-gas rumah kaca tersebut mengakibatkan terjadinya pemanasan global (Suwedi, 2005). Salah satu aktifitas manusia yang dapat memicu terjadinya pemanasan global adalah penebangan hutan. Penebangan hutan oleh masyarakat desa atau masyarakat pedalaman adalah untuk kepentingan pembangunan, untuk kepentingan pembukaan lahan pertanian, maupun digunakan sebagai kayu bakar (Suwedi, 2005).

Di tengah terdegradasinya hutan akibat penebangan, cangkang kemiri menjadi masalah baru sebagai limbah (Botahala, 2019) yang belum dimanfaatkan secara optimal. Menurut Prabarini dalam (Botahala, 2019), 64,57\% dari buah kemiri merupakan cangkang kemiri. Pada umumnya limbah cangkang kemiri ini dibakar begitu saja (Muliana, dkk., 2020). Hal ini dapat memberikan dampak terhadap terjadinya pemanasan global (Suwedi, 2005). Selain itu, cangkang kemiri juga telah dimanfaatkan sebagai karbon aktif dalam berbagai aplikasi (Loth Botahala, et al., 2016) dalam penjernihan minyak goreng bekas dengan variasi waktu kontak, (Bapa \& Botahala, 2019) menggunakan arang cangkang kemiri dengan aktivator $\mathrm{H}_{3} \mathrm{PO}_{4}$ dalam penjernihan minyak goreng bekas, dan (Botahala, et al., 2019) yang membandingkan efektivitas sekam padi dan cangkang kemiri dalam proses penjernihan air.

Pemanfaatan limbah cangkang kemiri sebagai briket telah dilakukan, di antaranya (Koly, et al., 2018) yang menguji porositas briket, dan (Kafama \& Botahala, 2020) yang menguji kadar air, kadar abu, porositas, nilai kalori. Dan masih banyak lagi penelitian tentang briket dari cangkang kemiri. Sehingga penting untuk diaplikasikan kepada masyarakat pedalaman dalam upaya pencegahan penebangan pohon sebagai bahan bakar.

Organisasi pemerintahan terendah adalah desa yang memiliki hak istimewa dalam mengurus sendiri urusan daerahnya termasuk urusan masyarakatnya (Arma dkk., 2020). Sehingga kesejahteraan masyrakat desa menjadi tanggungjawab secara langsung oleh aparatur pemerintahan desa. Desa Maikang dengan luas wilayah $7,15 \mathrm{Km}^{2}$ merupakan salah satu desa di wilayah kecamatan Alor Selatan kabupaten Alor (Anonim, 2016). Desa Maikang terletak di lembah dan dikelilingi oleh pohon kemiri yang adalah milik warga desa. Secara keseluruhan, luas areal kemiri di kecamatan Alor Selatan 1.311 Ha dengan jumlah produksi kemiri 887 ton (Anonim, 2016). Dengan demikian maka dapat dipastikan keberadaan limbah cangkang kemiri sangat melimpah.

Berdasarkan hasil survey bahwa desa Maikang juga merupakan jalur transit perdagangan tradisional, karena terletak di perbatasan antara kecamatan Mataru, kecamatan Alor Tengah Utara, dan kecamatan Alor Selatan. Hal ini dapat berakibat kepada pembakaran hutan secara sengaja untuk memperoleh kayu kering yang akan dijadikan bahan bakar dapur, memburu hewan liar, maupun membuka lahan baru, serta penebangan pohon secara sengaja untuk keperluan bahan bakar dapur. Sedangkang permasalahan yang ditemukan adalah cangkang kemiri tidak dapat dimanfaatkan dalam bentuk apapun termasuk tidak dijual oleh masyarakat sehingga perlu adanya pelatihan pembuatan briket cangkang kemiri sebagai bahan bakar alternatif.

Tujuan dari pengabdian masyarakat ini adalah untuk memberikan pengetahuan tentang pentingnya menjaga 
kelestarian hutan dengan cara memanfaatkan limbah sebagai bahan pengganti untuk keperluan rumah tangga.

\section{METODE KEGIATAN}

\section{Bahan dan alat}

Bahan yang digunakan dalam penelitian ini adalah cangkang kemiri yang dikumpulkan oleh masyarakat desa Maikang, tepung tapioka, dan air. Sedangkan alat yang digunakan adalah drum (hasil modifikasi drum bekas pakai), kuali, lumpang dan alu tradisional, kelengkapan tungku tradisional.

\section{Metode}

Tahapan pelaksanaan:

1. Ceramah dan tanya jawab tentang pemanasan global, sumber dan dampaknya terhadap lingkungan, serta pemanfaatan limbah cangkang kemiri sebagai briket pengganti kayu bakar yang disampaikan oleh narasumber dari penulis yakni atas nama Loth Botahala, S.T., M.Si.

2. Praktek pembuatan briket menggunakan limbah cangkang kemiri yang tersedia di sekitar masyarakat dengan melibatkan masyarakat secara langsung. Adapun prosedur kerja sebagai berikut:

a. Pembuatan arang

Pembuatan arang cangkang kemiri dilakukan secara tertutup menggunakan drum hasil modifikasi. Cangkang kemiri yang telah disiapkan dimasukan ke dalam drum dan dibakar menggunakan tungku manual/tradisional hingga berubah warna menjadi hitam pekat ( \pm 2 jam) agar terksturnya mudah dihaluskan. Arang yang telah terbentuk, kemudian didinginkan dan dihaluskan.

b. Pembuatan perekat

Tepung tapioka diencerkan dengan air secukupnya, kemudian dimasukkan ke dalam 2 liter air mendidih dan diaduk sampai terbentuk lem kanji yang siap digunakan.

c. Pembuatan briket

Arang cangkang kemiri yang telah diperoleh, ditambahkan perekat/lem dengan perbandingan $80: 20$, dimasukkan ke dalam cetakan lalu dipadatkan dan dikeringkan dibawah sinar matahari selama 2 hari.

\section{HASIL DAN PEMBAHASAN}

Kegiatan Pengabdian kepada Masyarakat ini dilaksanakan di Rumah Adat Desa Maikang kecamatan Alor Selatan kabupten Alor provinsi Nusa Tenggara Timur pada tanggal 26 Agustus 2020. Walaupun di antara kesibukan sebagai petani, warga masyarakat Desa Maikang tetap aktif mengikuti pelaksanaan kegiatan ini hingga akhir.

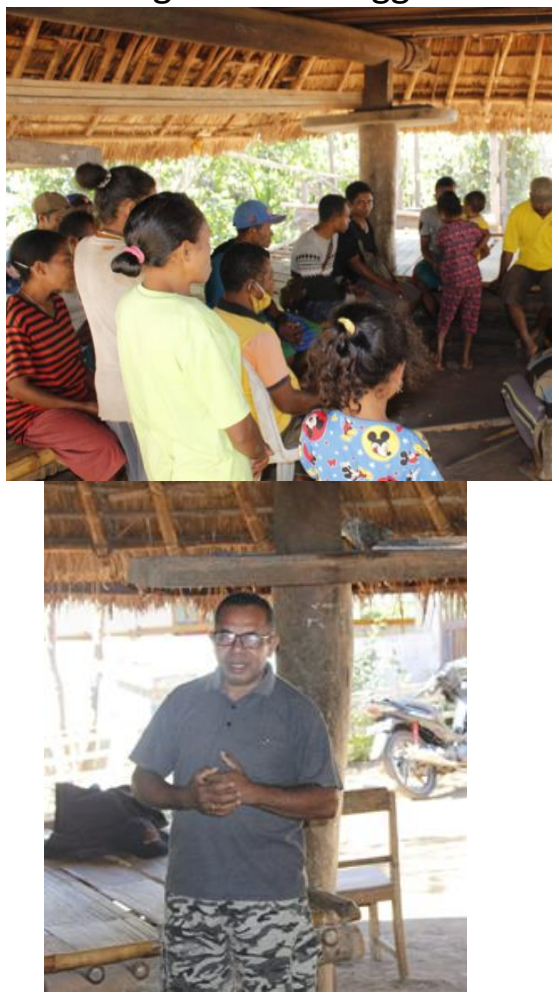

Gambar 1. Suasana pemaparan materi 


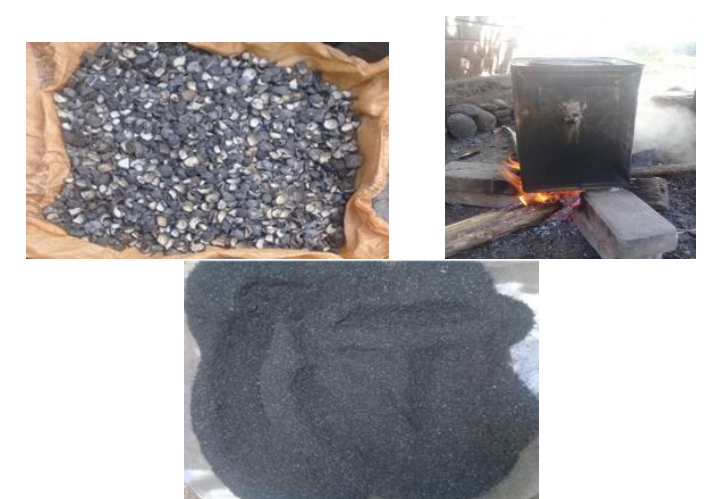

Gambar 2. Bahan dan proses pembuatan arang

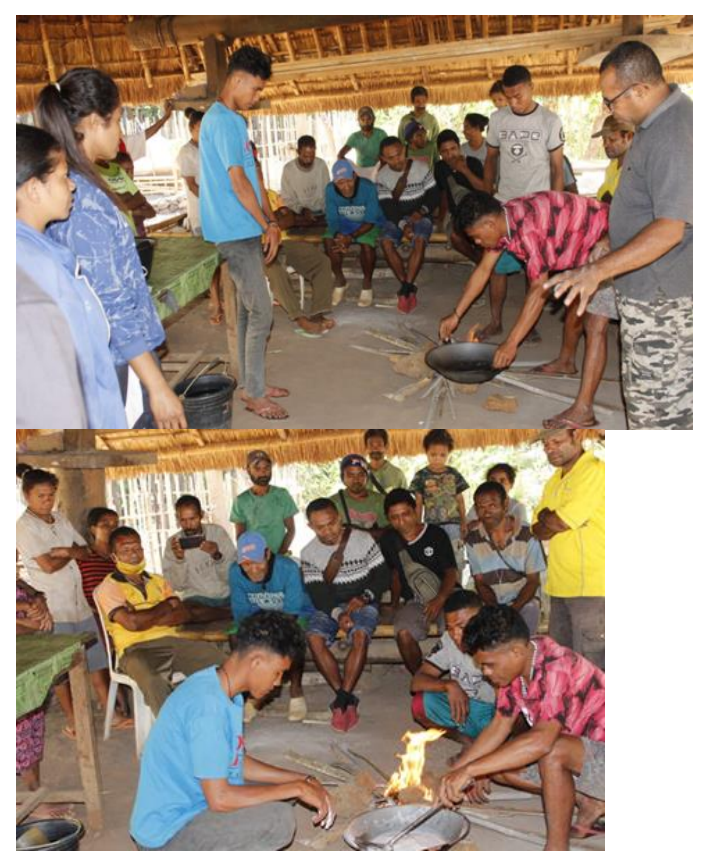

Gambar 3. Proses pembuatan perekat dari tepung kanji

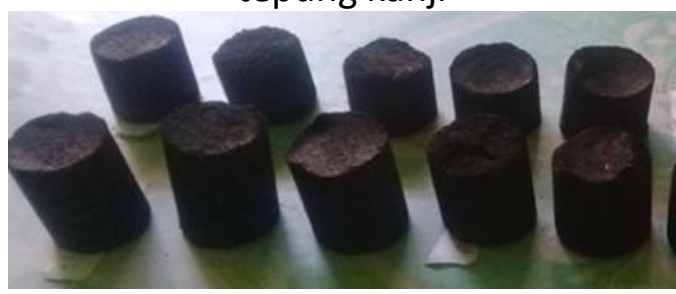

Gambar 4. Hasil pembuatan briket cangkang kemiri

Adapun manfat dari pembuatan briket di desa Maikang ini dapat diuraikan sebagai berikut:

\subsection{Membantu mengurangi limbah cangkang kemiri}

Limbah cangkang kemiri di kabupaten Alor belum dimanfaatkan secara maksimal sehingga belum memiliki nilai jual. Namun dengan adanya pelatihan pembuatan briket ini masyarakat telah

\subsection{Penghematan terhadap penebangan pohon}

Dengan adanya penjelasan tentang manfaat pohon sebagai paru-paru bumi dan pemanfaatan limbah sebagai briket pengganti kayu bakar telah memberikan pengetahuan kepada masyarakat untuk menjaga keseimbangan alam ini dengan tidak menebang pohon secara tidak teratur. Hal ini merupakan salah satu wujud partisipasi masyarakat dalam menghambat lajunya pemanasan global.

Akhir dari kegiatan pengabdian ini, sekretaris Desa Maikang mengucapkan terima kasih sekaligus menyatakan bahwa sesungguhnya di desa tersedia begitu banyak bahan yang sangat bermanfaat bagi masyarakat desa pada khususnya dan seluruh masyarakat pada umumnya jika ditopang dengan ilmu pengetahuan yang tepat.

\section{KESIMPULAN}

Adapun kesimpulan dari kegiatan ini adalah masyarakat Desa Maikang Kecamatan Alor Selatan Kabupaten AlorNTT telah memperoleh pengetahuan tentang fungsi pohon/hutan sebagai paruparu bumi sekaligus telah memperoleh pengetahuan tentang cara pembuatan briket dari limbah cangkang kemiri sebagai pengganti kayu bakar serta bersama melakukan kegiatan pembuatan briket tersebut.

\section{DAFTAR PUSTAKA}

Anonim. (2016). Alor Selatan Dalam Angka (1st ed.). Badan Pusat Statistik Kabupaten Alor. http://library1.nida.ac.th/termpa per6/sd/2554/19755.pdf

Arma, N. A., Sopang, J., \& Jaffisa, T. (2020). PENINGKATAN APARATUR DESA DALAM

PERENCANAAN 
PEMBANGUNAN DESA DI DESA KOTA RANTANG. RESWARA: Jurnal Pengabdian Kepada Masyarakat, 1(2), 91-95. http://jurnal.dharmawangsa.ac.id /index.php/reswara/article/view/ 573

Bapa, Y., \& Botahala, L. (2019). Effect Of The Contact Time of Candlenut Shell Charcoal And H3PO4 Activator As On The Purification Process Of Used Cooking Oil (Vol. 12, Issue 2).

Botahala, L. (2019). Perbandingan Efektivitas Daya Adsorpsi Sekam Padi Dan Cangkang Kemiri terhadap Logam Besi (Fe) pada Air Sumur Gali (1st ed.). Deepublish.

https://books.google.co.id/books ?hl=id\&lr=\&id=ilifDwAAQBAJ\&oi= fnd\&pg=PR5\&dq=Perbandingan+ Efektivitas+Daya+Adsorpsi+Seka $\mathrm{m}+$ Padi+Dan+Cangkang+Kemiri+T erhadap+Logam+Besi+(Fe)+Pada+ Air+Sumur+Gali\&ots=J1ngvsq7K6 \&sig=2stOBSi6odHGzBOGHDiXPAy L7UI\&redir_esc $=y \# v=$ one

Botahala, L., Malailak, Y., Silvia Maure, H., \& Karlani, H. (2019). Determination of Effectiveness Absorption of The Rice Husk And Hazelnut Shell to Purification Used Cooking Oil. Jurnal Akta Kimia Indonesia (Indonesia Chimica Acta), 12(1), 19. https://doi.org/10.20956/ica.v12i 1.6172
Kafama, E., \& Botahala, L. (2020). COMPARISON OF THE QUALITY OF COCONUT SHELL BRIQUETTES AND CANDLENUT SHELLS AS ALTERNATIVE FUELS. JOURNALS OF TECHNO ENTREPRENEUR ACTA TECHNO, 5(2), 100-103. https://journal.unifa.ac.id/index. php/tea/article/view/233

Koly, F. V. L., Karbeka, M., Mautuka, Z. A., Botahala, L., \& Mulle, Y. (2018). Porosity Test Mixture Based Charcoal Briquette Candlenut Shells (Aleurites Moluccana) and Charcoal Husk Rice (Oryza Sativa). E-Journal Universitas Tribuana Kalabahi, 1(1), 145-145. http://ojs.untribkalabahi.ac.id/in dex.php/ejournal/article/view/40

Loth Botahala, Nahor Padalowa, M. K. (2016). VARIATION OF CONTACT TIME OF THE CANDLENUT SHELL CHARCOAL PURIFICATION PROCESS USED COOKING OIL. Indonesia Chimica Acta, 9(2), 1519.

Muliana, N., Asfar, A. M. I. T., Asfar, A. M. I. A., Sari, A. M., Rismawati, \& Yusuf, A. N. (2020). Pemanfaatan Limbah Cangkang Kemiri Sebagai Briket Arang Bakar Masa Depan Melalui Pemberdayaan Ibu PKK Desa Matajang. 35-41.

Suwedi, N. (2005). Upaya Pencegahan Dan Penanggulangan Dampak Pemanasan Global. ..J. Tek. Ling. P3TL-BPPT, 6(2), 397-401. 
